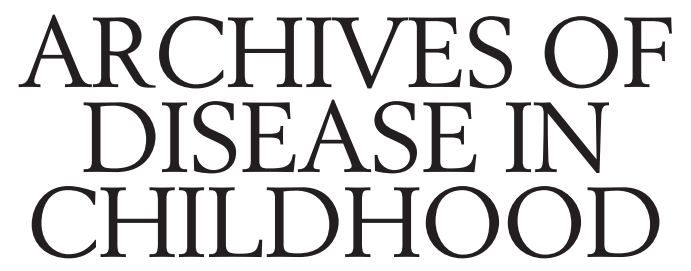

The Fournal of the Royal College of Paediatrics and Child Health

\title{
Annotation
}

\section{Pretrial liaison between doctors in alleged child abuse}

Few things are more likely to cause the heart to sink than a call to say that one will be needed for court in care proceedings. Parents may be fighting to keep not only the injured child but possibly other siblings and unborn children. The doctor caught up in all this, whether paediatrician, surgeon, psychiatrist, pathologist or general practitioner, can be sure that any opinions will be exposed to the closest scrutiny. The prospect of days wasted, turning up to find the case settled, postponed or cancelled, not to mention the time actually spent giving evidence, is an added cause for gloom. A recent development, that of meetings between experts - although designed primarily to smooth the process of the legal proceedings - also brings the prospect of reducing or obviating the need to attend court, and thus a considerable saving in time and stress.

Disagreement and misunderstandings are common Doctors may not always agree on aspects of individual cases of alleged abuse, especially if they happen to be instructed by different parties to the proceedings, where they may be privy to information not put before the court from their instructing party. Even when they do agree, attention to detail by a legal eye opens up the prospect for disagreement, real or apparent. In the past, doctors advising different parties in such cases were discouraged or actually disallowed from discussing the case with one another. This could sometimes lead to days being spent in court, discussing all aspects of the medical evidence, including both agreed and disagreed points. It tended to emphasise the adversarial nature of the proceedings, sometimes leading doctors to forget that, as experts, their job is to assist the court and to remain non-partisan. In $\operatorname{Re} A^{1}$ it was held that where the medical evidence points overwhelmingly to non-accidental injury, any expert who advises the parents and the court that the injury has an innocent explanation has a duty to ensure that all available material has been carefully considered and that any opinion can be objectively justified. In $\mathrm{Re} \mathrm{R}^{2}$ it was held that experts should not mislead by omissions. The expert should consider all the material facts in reaching conclusions and must not omit to consider the material facts that could detract from the concluded opinion. Furthermore, in $\operatorname{Re} A^{1}$ it was held that the expert should be wholly objective, and should not simply argue one side of a case. Where a report has been obtained by one party to the proceedings and is unfavourable to that party, it cannot be suppressed, and it must be filed with the court and served on all parties.
Proceedings concerning children are now seen as more inquisitorial, searching for the best solution for the children involved, and it has become the norm for courts in cases concerning children to direct that doctors should discuss a case well in advance of any final hearing. This imposes an obligation on a doctor to explain and discuss any opinions and the reasons for them with the other experts.

\section{Need for liaison}

Meetings between doctors may help to bridge gaps between different specialties or between different opinions. It is common (although by no means guaranteed) for differences of opinion to melt away once colleagues understand each other's reasons. If there is any prospect of this happening, it is desirable that it should occur before a court hearing, rather than wasting days of the court's and the doctors' time. Naturally, it is not the intention that the process of discussion should force doctors to change their opinions unwillingly. This kind of medical discussion can take place either before or after medical reports have been prepared, or at both stages. Discussion can take place on the telephone-perhaps a conference call—or at a special meeting.

\section{Prehearing meeting of experts}

Doctors involved in proceedings involving children should expect to attend a prehearing meeting with the other experts. ${ }^{3}$ Before such a meeting it is common for the legal experts to have focused on issues that may have been peripheral to points made in the medical reports. Once medical reports have been prepared, the solicitors or barristers are likely to produce lists of questions to be addressed by the doctors. Where possible, these lists are collated by the coordinator to avoid duplication, and are then provided to the experts in advance of the meeting and used as a basis for discussion at the meeting and (hopefully) answered at the meeting. The solicitor for the child(ren) and the guardian ad litem are usually given the task of coordinators; other lawyers do not usually attend the meeting.

Schedule of areas of agreement and disagreement It is usual for the coordinator to prepare a document containing the results of the discussion and answers to the questions posed in the form of a schedule of areas of agreement and disagreement. This is to ensure that the subsequent court hearing is focused on areas that have not been agreed, rather than roving over much wider territory. 

1. Jane Doe was admitted to the Blackford Royal Infirmary on 30 April 1996, aged 11 months. She was found to have a fractured skull, and an adjacent swelling of the scalp assumed to be a cephalhaematoma. The carers of the child were unable to account for these injuries
Agree:
Disagree:
Cannot comment:
Doctor C commented that the carers had in fact offered an explanation (the child banged her head against the cot when she was 2 weeks old) but this was not a plausible of explanation of the injuries
2. It is not possible to date the fracture of the skull from the appearances of the fracture itself on the plain $x$ rays of the skull
Agree: Doctor A, Doctor C
Disagree:
Cannot comment: Doctor B
3. The probability that the fractured skull was non-accidental is:
$51-70 \% \quad$ Doctor A
$71-90 \% \quad$ Doctor B
$91-100 \% \quad$ Doctor C

Figure 1 Case of suspected child abuse. Schedule of areas of agreement and disagreement.

There are no rules about the format, but in general the schedule consists of a series of statements or propositions, each usually one or two sentences long. Below each item, there is a list of the names of the doctors who agree, disagree, or are unable to comment. Inability to comment may be because the doctor has not had sight of specific items (such as photographs of bruises) or because the subject lies outside his or her area of expertise. A doctor may wish to add conditions or comments to a response, and these comments would usually be reported verbatim in the schedule, which when complete requires the signatures of all the contributing doctors (fig 1 ).

\section{Questions for the experts}

The questions provided by legal representatives can pose a real problem for doctors. Take, for example, a 12 month old child with an unusual degree of bruising on the face and the back, and a healed tear in the lip frenulum, in whom a skeletal survey shows a couple of healing rib fractures, with no convincing explanations for these injuries. The doctor forms the view, taking the overall picture into account, that it is likely that this is a case of child abuse. When asked to discuss each injury individually and to focus on whether the cause is likely to be non-accidental, doctors can find this somewhat artificial exercise frustrating. Another problem for doctors is being asked to give a precise figure of probability, something that is rarely done in clinical practice. A judge, however, may not be satisfied with a medical opinion that an injury is "on the balance of probability" non-accidental. This could mean anything from a $51 \%$ to a $100 \%$ degree of certainty, and a court may insist on the doctor not only attempting to make a more precise estimate of probability but also justifying the estimate, and explaining the mechanics of the injury-the possible causes and the most likely cause. The days when doctors could simply give an opinion and expect it to be accepted unchallenged have long since disappeared, and it is likely that one will have to back up opinions with data and clear reasoning.

\section{Conclusions}

The introduction of meetings between experts has reduced the areas of conflict and the need for doctors to attend court in cases of alleged child abuse. Meetings between experts work best if an agenda of questions is set by the legal representatives.

T J DAVID

Professor of Child Health and Paediatrics, University of Manchester, Honorary Consultant Paediatrician, Booth Hall Children's Hospital, Blackley, Manchester M9 7AA, UK

Barrister at Law,

Priory Chambers, 2 Fountain Court,

Steelhouse Lane, Birmingham B4 6DR, UK

D A HERSHMAN

Barrister at Law

1 Kings Bench Walk,

Temple, London EC4Y 7DB, UK

Correspondence to: Professor T J David, University Department of Child

Health, Booth Hall Children's Hospital, Charlestown Road, Blackley,

Manchester M9 7AA, UK. email: tim.david@dial.pipex.com

1 Re AB. (Child Abuse: Expert Witnesses) [1995] 1 FLR 181

2 Re R (A Minor) (Experts' Evidence) [1991] 1 FLR 291

3 Re C (Expert Evidence: Disclosure: Practice) [1995] 1 FLR 204.

\section{FETAL AND NEONATAL EDITION}

Ten years ago we published the first Fetal and Neonatal edition of Archives of Disease in Childhood in response to the large number of high quality papers we were receiving in that area. Now published bimonthly (and available to personal subscribers who do not subscribe to the standard edition) the readership continues to grow. In fact, many authors indicate that if their paper is accepted they would prefer it to be published in the Fetal and Neonatal edition.

We clarify here the types of papers considered more suitable for the Fetal and Neonatal edition:

- Basic science of the fetal and neonatal period including animal based research

- Clinical research in fetal medicine and care of the newborn, especially randomised controlled trials
- Outcome studies where the main variables against which outcome is assessed relate to the fetal or newborn period

- Genetics where the focus is on prenatal diagnosis; the molecular and clinical genetics of abnormalities recognisable in the fetal and neonatal periods; and outcomes of genetic conditions and syndromes recognisable in the fetal and neonatal periods.

We recognise that most general paediatricians have responsibilities for care of the newborn, and all paediatricians recognise the continuity of health and disease that stretches from fetal life to senility. Starting from this issue we highlight in the standard edition papers published in the concurrent Fetal and Neonatal edition that are of general interest as they relate to community, social, and neurodevelopmental paediatrics (see page 289). 